\title{
Factors affecting gastroesophageal reflux diagnosed by analysis of pepsin in the saliva of elderly patients with nasal feeding
}

\section{Yu Ding}

The Second Medical Centre,Chinese PLA General Hospital

Huiru Hou (D hhr610626@163.com )

The Second Medical Centre, Chinese PLA General Hospital

Miao Liu

Chinese PLA General Hospital

\section{Xiaoyuan Wang}

the Second Medical Centre,Chinese PLA General Hospital

Yue Xu

Medical School of Chinses PLA

Haiyan Shi

the Second Medical Centre,Chinse PLA Genral Hospital

Jiayu Guo

the Second Medical Centre,Chinese PLA General Hosppital

Haitao Du

the Second Medical Centre,Chinese PLA General Hospital

\section{Liyuan Wang}

the Second Medical Centre,Chinese PLA General Hospital

\section{Research article}

Keywords: elderly, enteral nutrition, pepsin, gastroesophageal reflux, nasal feeding

Posted Date: February 12th, 2020

DOl: https://doi.org/10.21203/rs.2.23282/v1

License: (c) (i) This work is licensed under a Creative Commons Attribution 4.0 International License.

Read Full License 


\section{Abstract}

\section{Background}

Elderly patients receiving nasal feeding have weaker physiological function and placement of a nasogastric tube destroys the natural barrier of the cardia-esophageal sphincter. Pepsin in saliva may reflect gastroesophageal reflux disease (GERD). This study investigated pepsin levels in saliva of elderly patients with nasal feeding and analyzed the relevant factors.

\section{Methods}

This was a cross-sectional study. Patients admitted to the Chinese PLA General Hospital from April 2018 to October 2018 who received nasal feeding were included. One $\mathrm{ml}$ of saliva was collected from each patient during fasting in the morning and 1 hour after lunch for 3 consecutive days. Pepsin was quantified by enzyme-linked immunosorbent assay (ELISA). The patients were divided into two groups ( $\geq 7.75 \mathrm{ug} / \mathrm{ml}$ or $<7.75 \mathrm{ug} / \mathrm{ml}$ ) based on the median pepsin. Baseline and clinical factors were compared.

\section{Results}

The mean age of the patients was $91.09 \pm 4.91$ years. There were statistical differences in diabetes and feeding methods between the two groups. There was a positive correlation between the morning and postprandial pepsin levels $(r=0.442, P<0.001)$. Multivariate analysis showed that the risk factors for higher pepsin levels were diabetes (odds ratio (OR): $2.67 ; 95 \% \mathrm{Cl}: 1.225-5.819, \mathrm{P}=0.013$ ) and nasal feeding methods (OR: $2.475 ; 95 \% \mathrm{Cl}: 1.183-5.180, \mathrm{P}=0.016)$.

\section{Conclusions}

For patients undergoing nasal feeding who are older than 80 years, the fasting and 1-hour postprandial pepsin concentration was consistent. Diabetes and feeding methods are risk factors for high pepsin levels, which may indicate GERD.

\section{Background}

The elderly aged over 80 have the highest prevalence and fastest growing rates of disability [1]. Due to physiological dysfunction and multiple diseases, it is often necessary to support these patients with enteral nutrition. Nasogastric gavage (NG) is a common method of providing enteral nutrition; however, placement of the nasogastric tube can destroy the natural barrier of the cardia lower esophageal sphincter, increasing the risk of food and stomach acid reflux [2]. Moreover, elderly patients with chronic diseases have prominent comorbidities and severe physiological decline which increases the risk of gastroesophageal reflux disease (GERD) [3]. GERD is defined as symptoms or mucosal damage produced by the abnormal reflux of gastric contents into the esophagus or beyond [4]. It has also been reported that GERD is part of the most prevalent co-morbid conditions in elderly patients [5]. 
GERD incidence varies in different regions and races. However, the overall incidence increases with age [6-10]. In China, the prevalence of GERD has increased over the past decade by at least $50 \%{ }^{[11]}$. GERD not only seriously affects the quality of life of elderly patients [11], but is also closely associated with respiratory symptoms, such as chronic cough [11, 12], which is one of the risk factors for aspiration [13]. GERD also imposes a heavy economic burden $[12,14-16]$. Diagnosis of GERD usually involves assessment of a combination of clinical symptoms, response to acid suppression, and objective testing with upper endoscopy and esophageal pH monitoring [17]. However, invasive methods, such as esophageal reflux monitoring, endoscopy and esophageal manometry can be difficult. While non-invasive methods, including a GERD diagnostic questionnaire and proton pump inhibitors (PPI) may not be accurate. Thus, diagnosis can be inappropriate, expensive and painful [18]. Elderly patients often have complicated conditions, and their symptoms are atypical, which can also increase the difficulty in diagnosis of GERD [19].

In recent years, a number of studies have confirmed that human salivary pepsin concentration can be used as a non-invasive, economic, fast, and effective method for diagnosing GERD [15, 20, 21]. Li et al. $[22,23]$ detected the pepsin concentration in human saliva by enzyme-linked immunosorbent assay (ELISA). The sensitivity of pepsin in the diagnosis of GERD was $93.8 \%$ and the specificity was $46.2 \%$. This suggested that the sensitivity of pepsin concentration was superior to a diagnostic questionnaire and proton pump inhibitor (PPI) test. Jamal et al. [18] reported that the postprandial pepsin level more accurately reflected GERD, which can be used as an auxiliary diagnostic method for GERD, thereby reducing the need for invasive and expensive diagnostic procedures.

This study aimed to analyze the influencing factors of GERD in elderly patients with nasal feeding. This was undertaken by measuring the concentration of pepsin in saliva, and analysis of factors that led to relatively high levels of pepsin in their saliva. This information should provide a reliable basis for reducing the incidence of GERD in elderly patients with nasal feeding, as well as alleviating related symptoms.

\section{Methods}

\section{Patients}

This was a cross-sectional study. Patients who received enteral nutrition through a nasogastric tube from August 2018 to September 2018 at the Chinese PLA General Hospital (Beijing, China) were enrolled. The study protocol was approved by the Ethics Committee of the Chinese PLA General Hospital (S2018-09701), and all patients or their families signed informed consent.

\section{Inclusion and exclusion criteria}

Inclusion criteria: 1) aged $\geq 80$ years; 2) nasal feeding through a nasogastric tube for more than 1 month;

3) stable condition during this study without fluctuations in vital signs; and 4) had not drunk alcohol, 
smoked or eaten spicy food during the past six months. Exclusion criteria: 1) patients with gastrointestinal decompression; 2) patients with major gastrectomy; or 3) patients who underwent PPI test in the past month.

\section{Study design}

Patients were tested for pepsin concentration for 3 consecutive days, during fasting in the morning and $1 \mathrm{~h}$ after lunch (a total of 6 saliva samples were collected from each patient).

Mean values of pepsin concentrations during fasting in the morning and $1 \mathrm{~h}$ after lunch were calculated respectively for each patient. Patients were divided into 2 groups based on the median of the mean values of pepsin concentrations. Baseline and clinical factors were compared between the groups.

\section{Data collection}

A unified data collection form was used to gather general clinical data from patients based on case data, nursing records, and bedside visits. Data collected included age, history of diabetes, history of

hypertension, mechanical ventilation, total daily feeding volume, feeding methods, the ratio of the length of internal gastric tube to its height, type of gastric tube type, and duration of gastric tube placement.

\section{Specimen collection and processing}

Two trained nurses collected the saliva specimens. In order to avoid the effects of teeth brushing and mouthwash on the pepsin concentrations in the mouth, a suction tube with vacuum aspiration was used to suck out saliva from the throats of all patients. No specimen contained less than $1 \mathrm{ml}$. The specimens were stored at $4 \mathrm{C}$, and mixed 4 times with $0.1 \%$ dithiothreitol (DTT) for $30 \mathrm{~min}$. After using a $37 \mathrm{C}$ water bath for $10 \mathrm{~min}$, the mixture was centrifuged at $4 \mathrm{C}$ and $5000 \mathrm{rpm}$ for $7 \mathrm{~min}$, and the supernatant was tested. The concentration of pepsin in the supernatant was detected by ELISA. The human secretion pepsin ELISA kit was purchased from Beijing Jing lai Hua ke Biological Co., Ltd (Beijing, China). The automatic microplate reader was Denley Dragon Wellscan MK 3 (Thermo, Finland), the Thermo Scientific Wellwash 4 Mk2 microplate washer was used (Thermo, Finland), and the data were analyzed by Ascent software (Thermo LabSystems Inc., MA, USA).

\section{Statistical analysis}

Continuous variables underwent a probability (PP) plot, quantile-quantile (Q-Q) plot, and the Shapiro-Wilk test for normality. Variables which conform to normal distributions were expressed as mean \pm standard deviation (SD) and compared with Student t test. Variables which do not conform to normal distributions were expressed as meadian (lower quartile, upper quartile), and compared with Mann-Whitney U test. Categorical variables were expressed as number and percentages and compared with Chi-square test. Spearman correlation analysis was performed to investigate the association of fasting and postprandial pepsin levels in saliva, because they did not conform to normal distributions. A logistic regression model was used for univariate and multivariate analysis to find independent factors affecting higher pepsin 
levels. Statistical significance was defined at $P<0.05$. All data were analyzed using SPSS 17.0 software (SPSS, Chicago, USA).

\section{Results}

\section{Inclusion of the participants}

There were 156 male patients who met the inclusion criteria and were enrolled. During the study, 23 patients were excluded due to various reasons. Seven patients were unable to produce saliva specimens for 3 consecutive days, 4 patients had changes in condition during this study, 6 patients changed their feeding frequency or feeding method, 2 patients received accidental percutaneous endoscopy gastrostomy tube removal, 2 patients presented with increased mechanical ventilation, and 1 patient died suddenly (Fig. 1).

\section{Clinical characteristics in the two groups}

Table 1 shows the clinical characteristics of the 133 patients. As a positive threshold for salivary pepsin diagnosis of GERD has not been determined, we divided the patients into 2 groups, $\geq 7.75 \mathrm{ug} / \mathrm{ml}$ or $<7.75$ $\mathrm{ug} / \mathrm{ml}$, based on the median pepsin concentration. There were no statistical differences in age between the 2 groups ( $91.8 \pm 4.37$ vs. $90.8 \pm 4.51, P=0.220)$, whereas statistical differences were found in diabetes $(P=0.022)$ and feeding methods $(P=0.034)$ between the two groups. 
Table 1

Demographic and clinical characteristics of the 133 enrolled patients

\begin{tabular}{|c|c|c|c|}
\hline Variables & $\begin{array}{l}\text { Pepsin concentration } \geq \\
7.75^{\mathrm{a}} \mathrm{ug} / \mathrm{ml}(\mathrm{n}=55)\end{array}$ & $\begin{array}{l}\text { Pepsin concentration < } \\
7.75 \mathrm{ug} / \mathrm{ml}(\mathrm{n}=78)\end{array}$ & $\mathbf{P}$ \\
\hline Age (year) & $91.8 \pm 4.4$ & $90.8 \pm 4.5$ & 0.220 \\
\hline Esophageal hiatal hernia & $2(3.63)$ & $2(2.56)$ & 0.721 \\
\hline Hyperlipemia & $7(12.72)$ & $11(14.10)$ & 0.819 \\
\hline $\begin{array}{l}\text { Family history of } \\
\text { gastroesophageal } \\
\text { disease }\end{array}$ & $4(7.27)$ & $7(8.97)$ & 0.726 \\
\hline OSAS & $1(1.82)$ & $1(1.28)$ & 0.802 \\
\hline Drugs related to GERD ${ }^{b}$ & $16(29.09)$ & $29(37.18)$ & 0.332 \\
\hline Diabetes & $14(25.45)$ & $35(44.87)$ & 0.022 \\
\hline Hypertension & $38(69.09)$ & $48(61.54)$ & 0.370 \\
\hline Mechanical ventilation & $19(34.55)$ & $36(46.15)$ & 0.213 \\
\hline $\begin{array}{l}\text { Total daily feeding } \\
\text { volume }(\mathrm{ml})\end{array}$ & & & 0.297 \\
\hline$\leq 500$ & $6(10.91)$ & $16(20.51)$ & \\
\hline $501-1500$ & $35(63.63)$ & $47(60.26)$ & \\
\hline$>1500$ & $14(25.45)$ & $15(19.23)$ & \\
\hline Feeding method & & & 0.028 \\
\hline Syringe injection & $36(65.45)$ & $36(46.15)$ & \\
\hline Nasal pump feeding & $19(34.55)$ & $42(53.85)$ & \\
\hline Insertion length/height & & & 0.774 \\
\hline$<0.35$ & $24(43.64)$ & $36(46.15)$ & \\
\hline$\geq 0.35$ & $31(56.36)$ & $42(53.85)$ & \\
\hline
\end{tabular}

OSAS: obstructive sleep apnea syndrome; GERD: gastroesophageal reflux disease

a $7.75 \mathrm{ug} / \mathrm{ml}$ is the median of pepsin content.

${ }^{\mathrm{b}}$ mainly including nonsteroidal anti-inflammatory drugs, aspirin and anticholinergic agents.

${ }^{c} 512$ days is the median time of stomach tube placement (day). 


\begin{tabular}{|c|c|c|c|}
\hline Variables & $\begin{array}{l}\text { Pepsin concentration } \geq \\
7.75^{\mathrm{a}} \mathrm{ug} / \mathrm{ml}(\mathrm{n}=55)\end{array}$ & $\begin{array}{l}\text { Pepsin concentration < } \\
7.75 \mathrm{ug} / \mathrm{ml}(\mathrm{n}=78)\end{array}$ & $\mathbf{P}$ \\
\hline Tube diameter (mm) & & & 0.092 \\
\hline 4.46 & $30(4.55)$ & $31(39.74)$ & \\
\hline 3.23 & $25(45.45)$ & $47(60.26)$ & \\
\hline $\begin{array}{l}\text { Stomach tube placement } \\
\text { time (day) }\end{array}$ & & & 0.062 \\
\hline$\geq 512^{c}$ & $22(0.4)$ & $44(56.41)$ & \\
\hline$<512$ & $33(0.6)$ & $34(43.59)$ & \\
\hline \multicolumn{4}{|c|}{ OSAS: obstructive sleep apnea syndrome; GERD: gastroesophageal reflux disease } \\
\hline \multicolumn{4}{|c|}{ a $7.75 \mathrm{ug} / \mathrm{ml}$ is the median of pepsin content. } \\
\hline \multicolumn{4}{|c|}{ b mainly including nonsteroidal anti-inflammatory drugs, aspirin and anticholinergic agents. } \\
\hline
\end{tabular}

\section{Comparison of fasting and postprandial pepsin levels}

The fasting and postprandial pepsin levels were $4.053(2.163 ; 8.467) \mathrm{ug} / \mathrm{ml}$ and $5.108(2.458 ; 7.928)$ $\mathrm{ug} / \mathrm{ml}$, respectively, showing no significant differences $(P=0.175)$. The Spearman correlation coefficient (r) was equal to $0.442, P<0.001$, indicating a positive correlation between these two measurements.

\section{Logistic multivariate regression analysis of pepsin content in elderly patients with long-term nasal feeding}

Taking the pepsin concentration as the dependent variable, variables with $\mathrm{P}<0.1$ in the univariate analysis were selected as independent variables and included in the logistic regression model.

The results showed that the main factors influencing the pepsin concentration in saliva of elderly patients with long-term nasal feeding were diabetes (OR: 2.670, Cl: 1.225-5.819) and nasal feeding method (OR: 2.475, Cl: 1.183-5.180) (Table 2). 
Table 2

Multivariate analysis of factors influencing pepsin in saliva

\begin{tabular}{|lllll|}
\hline Factors & & OR & $95 \% \mathrm{Cl}$ & $\mathrm{P}$ \\
Diabetes & & 2.670 & $1.225-5.819$ & 0.013 \\
Feeding methods & Nasal pump feeding & 1 & & \\
& Syringe injection & 2.475 & $1.183-5.180$ & 0.016 \\
\hline OR = odds ratio; $\mathrm{Cl}=$ confidence interval & & & \\
\hline
\end{tabular}

\section{Discussion}

This cross-sectional study involved 133 patients aged over 80 undergoing nasal feeding. We measured the pepsin level in saliva as a simple indicator of GERD to investigate factors related to GERD in these patients. We found that factors independently related to a relatively high level of pepsin in saliva were diabetes (OR: $2.67 ; 95 \% \mathrm{Cl}: 1.225-5.819, \mathrm{P}=0.013)$ and nasal feeding methods (OR: $2.475 ; 95 \% \mathrm{Cl}$ : $1.183-$ $5.180, P=0.016)$.

Invasive tests for GERD diagnosis are difficult and even impossible in very elderly patients, such as those included here, so we used pepsin level as an indicator of GERD. Due to a lack of a gold standard for normal pepsin level in elderly people, the patients were divided into two groups according to the median pepsin level. Previous studies have suggested that the concentration of pepsin in saliva samples changes at different time periods [18, 24]; however, there is still no consensus on the optimal collection time [18, $20,21]$. Hayat et al. [18] used a PPI test to determine pepsin, and suggested that the positive detection rate and concentration $1 \mathrm{~h}$ after a meal are higher than during the fasting state in the morning, therefore, they recommended collecting saliva samples $1 \mathrm{~h}$ after meal. However, $\mathrm{Na}$ et al. [24] believed that the concentration of pepsin upon waking was higher than $1 \mathrm{~h}$ after a meal when GERD symptoms occur. To resolve this difference, we collected the patient's samples during fasting in the morning and $1 \mathrm{~h}$ after lunch. The results showed that the pepsin levels in the morning and $1 \mathrm{~h}$ after lunch were highly positively correlated, with no significant difference. This difference with the previous studies might be because of the differences in the populations. In elderly patients with nasal feeding, the concentration of pepsin accumulated in the mouth and throat likely remained relatively stable due to decreased activity, increased time in bed, and decreased saliva secretion. Therefore, we speculate that the pepsin content in the saliva of elderly patients with nasal feeding is basically stable throughout the day and responds to reflux.

Age was not independently related to increased salivary pepsin in this study. However, other studies on different age groups have suggested that age does have an influence GERD. In a previous study, prevalence was significantly higher in subjects aged more than 50 years [10]. Another study [3] indicated that increased age was associated with the prevalence of GERD, and the mechanisms of increased GERD disease in older patients intensified the underlying diseases, disturbed esophageal motility, and 
decreased salivary secretion. However, there are few studies concerning patients aged $\geq 80$ years. In our study, age was not a risk factor because there was no significant difference in the degree of underlying diseases and physiological functions of the patients aged $\geq 80$ years. In other words, when patients are aged $\geq 80$ years, their condition is complex, which attenuates or disperses the effects of age.

According to a previous study, diabetic patients are more prone to GERD [25]. This is in agreement with the results of this study which found that diabetes was related to higher levels of pepsin in the saliva. Hyperglycemia affects autonomic function and gastrointestinal hormone secretion, resulting in insufficient gastric motility in patients $[3,6,26]$. Insufficient gastric motility is one pathogenic mechanism of GERD. In addition, obesity is an important risk factor for GERD, and obesity and type 2 diabetes are closely associated [25]. This suggests that patients with a history of diabetes should be specifically concerned with the presence of GERD during medical and nursing care.

Feeding method was also shown to be related to a higher level of pepsin in saliva. It has been reported that the use of a stomach tube with a small outer diameter can reduce the occurrence of complications, such as reflux [27]. However, the results of this study showed that the outer diameter of the gastric tube was not a factor affecting the content of pepsin. Perhaps the sample size of this study was too small, and the diameters of the two gastric tubes were not remarkably different. Therefore, we could not reach a similar conclusion. Previous studies in Chinese have suggested that a nasal feeding pump can inject liquid food into the stomach at a constant rate and slowly, which is superior to syringe injection in preventing intestinal nutrition complications. The results of our study also showed a high risk of high concentrations of pepsin in the saliva of syringe-fed patients. We hypothesize that because syringe feeding injects food into the stomach quickly, causing a rapid increase in the pressure applied to stomach, this leads to increased risk of GERD. In contrast, using a nasal feeding pump not only reduces the pressure of the food on the lower esophageal sphincter, but also slows down the rate of blood glucose in the patient.

There were several limitations in this study. First, the sample size was not very large, and we did not compare the results with a healthy control group. Second, due to the gold standard diagnostic method for GERD being invasive and not suitable for patients aged 80 and over, we could only choose the level of pepsin in saliva to indicate GERD. As the level of pepsin that indicates GERD has not been agreed we cannot definitely say that the patients in the $\geq 7.75 \mathrm{ug} / \mathrm{ml}$ pepsin group had GERD. Third, this was a cross-sectional study and lacked follow-up data. Fourth, the patients included in this study were all male, and the results might not apply to female patients. Finally, only the use of non-steroidal anti-inflammatory drugs (NSAID), aspirin and anticholinergic drugs on the level of pepsin were analyzed. Other drugs with potential effects were not included in the analysis. These may cause some bias to the results.

\section{Conclusions}

In conclusion, for patients undergoing nasal feeding who were older than 80 years, diabetes and feeding methods were risk factors for increased pepsin level, which may indicate GERD. Age had an insignificant 
effect on pepsin level in this population. The concentration of pepsin in the saliva remained consistent throughout the day and was not altered by feeding.

\section{Abbreviations}

ABBREVIATIONS

GERD, gastroesophageal reflux disease

ELISA, enzyme-linked immunosorbent assay

NG, Nasogastric gavage

PPI, proton pump inhibitors

DTT, dithiothreitol

PP, probability plot

Q-Q, quantile-quantile

SD, standard deviation

NSAID, non-steroidal anti-inflammatory drugs

\section{Declarations}

Ethics approval and consent to participate

The study protocol was approved by the Ethics Committee of the Chinese PLA General Hospital (S2018097-01), and all patients or their families signed informed consent.

\section{Consent for publication}

Not applicable.

\section{Availability of data and materials}

The datasets used and/or analysed during the current study are available from the corresponding author on reasonable request.

\section{Conflict of interest}

The author declares no conflict of interest.

\section{Funding}


Not applicable.

\section{Authors' contributions}

DY substantially contributed to design, drafted the manuscript for important content and acquisition of data and was a major contributor in writing the manuscript. HHR contributed to conception, provided the fund support, ensured the quality of content, critically revised the manuscript. LM contributed to analysis and design of data. WXY contributed to acquisition, entry and statistics of data. XY substantially contributed to design, the acquisition, entry and statistics of data. SHY contributed to acquisition, entry and statistics of data. GJY contributed to acquisition, entry and statistics of data. DHT contributed to revised the manuscript, the entry and statistics of data. WLY contributed to acquisition, entry of data. All authors read and approved the final manuscript.

\section{Acknowledgement}

We acknowledge the leaders of the departments where the patients were enrolled for the support of this study; we thank Professor Gangshi Wang for the guidance of the design of the thesis, as well as the guidance of the result statistics from teacher Miao Liu, and the support and help of the tutor Prof. Huiru Hou and other colleagues.

\section{References}

1. Liu D, Tan J, Guo Y, Ye G, Zhu L, Zhang J, et al. [The contributing risk factors, prevention and treatment of functional dependence among the oldest-old and elderly subjects]. Zhonghua nei ke za zhi. 2014;53:772-7.

2. Pryor LN, Ward EC, Cornwell PL, O'Connor SN, Finnis ME, Chapman MJ. Impact of nasogastric tubes on swallowing physiology in older, healthy subjects: A randomized controlled crossover trial. Clinical nutrition (Edinburgh, Scotland). 2015;34:572-8.

3. Bashashati M, Sarosiek I, McCallum RW. Epidemiology and mechanisms of gastroesophageal reflux disease in the elderly: a perspective. Annals of the New York Academy of Sciences. 2016;1380:230-4.

4. Katz PO, Gerson LB, Vela MF. Guidelines for the diagnosis and management of gastroesophageal reflux disease. The American journal of gastroenterology. 2013;108:308-28; quiz 29.

5. Moore KL, Boscardin WJ, Steinman MA, Schwartz JB. Patterns of chronic co-morbid medical conditions in older residents of U.S. nursing homes: differences between the sexes and across the agespan. The journal of nutrition, health \& aging. 2014;18:429-36.

6. Ikeda Y, Furukawa S, Sakai T, Niiya T, Miyaoka H, Miyake T, et al. Age and Prevalence of Esophageal Reflux Disease in Japanese Patients with Type 2 Diabetes Mellitus: The Dogo Study. Digestive diseases and sciences. 2016;61:3530-6.

7. Wang HY, Leena KB, Plymoth A, Hergens MP, Yin L, Shenoy KT, et al. Prevalence of gastro-esophageal reflux disease and its risk factors in a community-based population in southern India. BMC 
gastroenterology. 2016;16:36.

8. Tan VP, Wong BC, Wong WM, Leung WK, Tong D, Yuen MF, et al. Gastroesophageal Reflux Disease: Cross-Sectional Study Demonstrating Rising Prevalence in a Chinese Population. Journal of clinical gastroenterology. 2016;50:e1-7.

9. Moore KL, Boscardin WJ, Steinman MA, Schwartz JB. Age and sex variation in prevalence of chronic medical conditions in older residents of U.S. nursing homes. Journal of the American Geriatrics Society. 2012;60:756-64.

10. Eusebi LH, Ratnakumaran R, Yuan Y, Solaymani-Dodaran M, Bazzoli F, Ford AC. Global prevalence of, and risk factors for, gastro-oesophageal reflux symptoms: a meta-analysis. Gut. 2018;67:430-40.

11. Yadlapati R, Dakhoul L, Pandolfino JE, Keswani RN. The Quality of Care for Gastroesophageal Reflux Disease. Digestive diseases and sciences. 2017;62:569-76.

12. Hsu WT, Lai CC, Wang YH, Tseng PH, Wang K, Wang CY, et al. Risk of pneumonia in patients with gastroesophageal reflux disease: A population-based cohort study. PloS one. 2017;12:e0183808.

13. Satou Y, Oguro H, Murakami Y, Onoda K, Mitaki S, Hamada C, et al. Gastroesophageal reflux during enteral feeding in stroke patients: a 24-hour esophageal pH-monitoring study. Journal of stroke and cerebrovascular diseases : the official journal of National Stroke Association. 2013;22:185-9.

14. Colak Y, Nordestgaard BG, Laursen LC, Afzal S, Lange P, Dahl M. Risk Factors for Chronic Cough Among 14,669 Individuals From the General Population. Chest. 2017;152:563-73.

15. Luo HN, Yang QM, Sheng Y, Wang ZH, Zhang Q, Yan J, et al. Role of pepsin and pepsinogen: linking laryngopharyngeal reflux with otitis media with effusion in children. The Laryngoscope. 2014;124:E294-300.

16. Mulrennan SA, Knuiman MW, Divitini ML, Cullen DJ, Hunter M, Hui J, et al. Gastro-oesophageal reflux and respiratory symptoms in Busselton adults: the effects of bodyweight and sleep apnoea. Internal medicine journal. 2012;42:772-9.

17. Badillo R, Francis D. Diagnosis and treatment of gastroesophageal reflux disease. World journal of gastrointestinal pharmacology and therapeutics. 2014;5:105-12.

18. Hayat JO, Gabieta-Somnez S, Yazaki E, Kang JY, Woodcock A, Dettmar P, et al. Pepsin in saliva for the diagnosis of gastro-oesophageal reflux disease. Gut. 2015;64:373-80.

19. Achem SR, DeVault KR. Gastroesophageal reflux disease and the elderly. Gastroenterology clinics of North America. 2014;43:147-60.

20. Saritas Yuksel E, Hong SK, Strugala V, Slaughter JC, Goutte M, Garrett CG, et al. Rapid salivary pepsin test: blinded assessment of test performance in gastroesophageal reflux disease. The Laryngoscope. 2012;122:1312-6.

21. Calvo-Henriquez C, Ruano-Ravina A, Vaamonde P, Martinez-Capoccioni G, Martin-Martin C. Is Pepsin a Reliable Marker of Laryngopharyngeal Reflux? A Systematic Review. Otolaryngology-head and neck surgery : official journal of American Academy of Otolaryngology-Head and Neck Surgery. 2017;157:385-91. 
22. Wang L, Liu X, Liu YL, Zeng FF, Wu T, Yang CL, et al. Correlation of pepsin-measured laryngopharyngeal reflux disease with symptoms and signs. Otolaryngology-head and neck surgery : official journal of American Academy of Otolaryngology-Head and Neck Surgery. 2010;143:765-71.

23. Li XP, Chen SJ, Wang L, Liu X, Liu YL, Zeng FF. [Pepsin immunoassay in the sputum for detection of laryngopharyngeal reflux]. Zhonghua er bi yan hou tou jing wai ke za zhi = Chinese journal of otorhinolaryngology head and neck surgery. 2009;44:99-104.

24. Na SY, Kwon OE, Lee YC, Eun YG. Optimal timing of saliva collection to detect pepsin in patients with laryngopharyngeal reflux. The Laryngoscope. 2016;126:2770-3.

25. Sun XM, Tan JC, Zhu Y, Lin L. Association between diabetes mellitus and gastroesophageal reflux disease: A meta-analysis. World journal of gastroenterology. 2015;21:3085-92.

26. Careyva B, Stello B. Diabetes Mellitus: Management of Gastrointestinal Complications. American family physician. 2016;94:980-6.

27. Ibanez J, Penafiel A, Marse P, Jorda R, Raurich JM, Mata F. Incidence of gastroesophageal reflux and aspiration in mechanically ventilated patients using small-bore nasogastric tubes. JPEN Journal of parenteral and enteral nutrition. 2000;24:103-6.

\section{Figures}




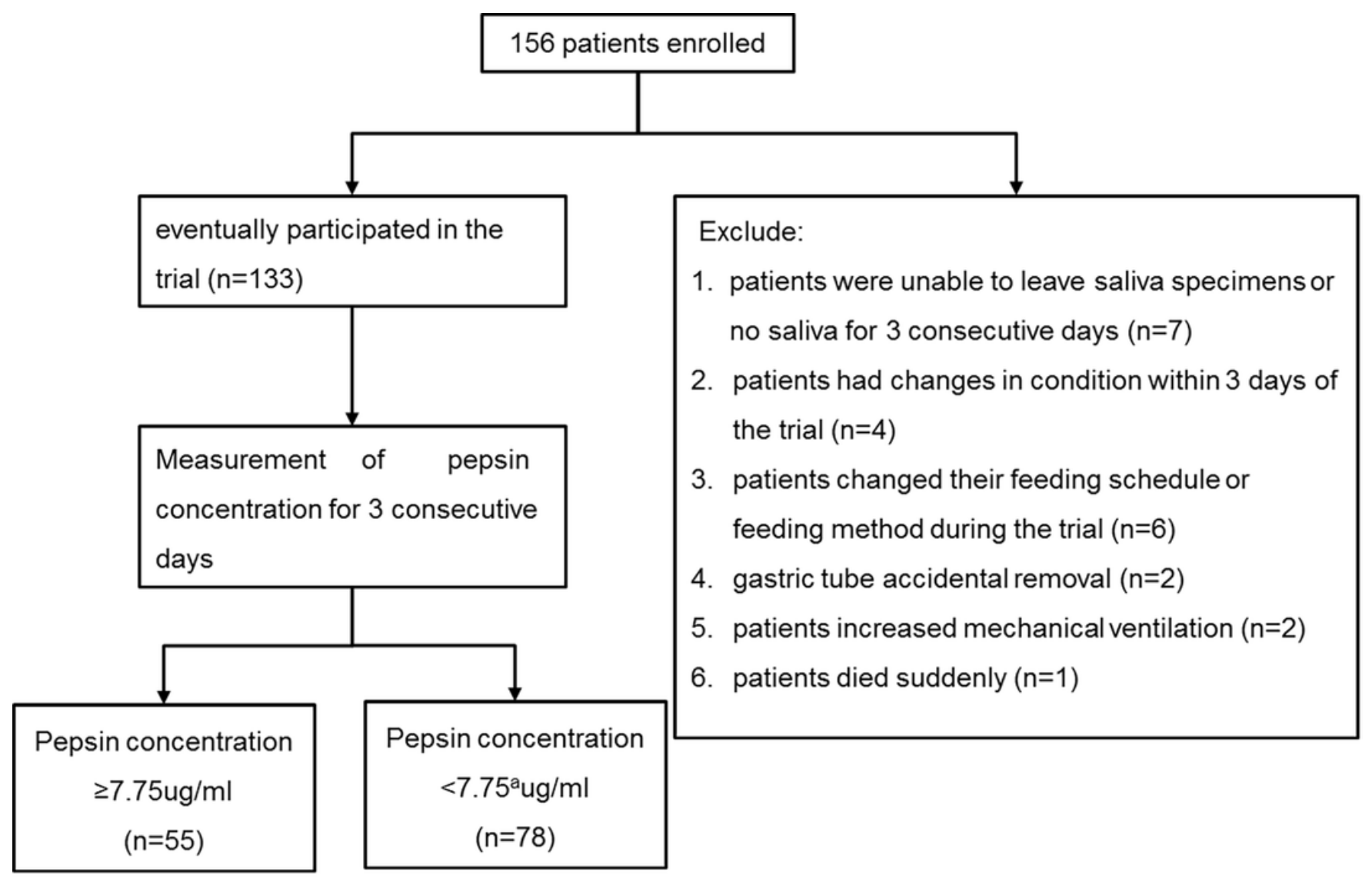

(Figure 1. Flow chart of patient inclusion)

\section{Figure 1}

Flow chart showing the inclusion of patients in the study. 